\title{
Umm Ar-Rasas: The Application of Integrated Methodologies for the Valorization of a Unesco Site
}

\author{
Gabrielli R and Greco G* \\ Institute for Technologies Applied to Cultural Heritage, National Research Council (ITABC CNR), Italy
}

Submission: August 02, 2018; Published: September 05, 2018

*Corresponding author: Greco G, Institute for Technologies Applied to Cultural Heritage, National Research Council (ITABC CNR) - Montelibretti (RM), Italy, Email: giorgia.greco89@gmail.com

\begin{abstract}
The research expedition of the CNR-ITABC at the archaeological site of Umm ar-Rasas in Jordan started in 2013. The project's focus has been the survey and documentation of two Byzantine churches and their mosaic floors. Different investigation techniques, such as laser scanning and photogrammetry, have been reciprocally integrated, to create geometric models enabling the interpretation of data related to the masonry and the mosaic floors, as well as to the documentation of the archaeological area. The results obtained from the work of the research group will be useful to plan and develop restoration projects for the protection and valorization of the UNESCO site. An important part of the project has involved the planning of future interventions: actions to arrest the mosaics' decay, such as the identification of the critical features in the conservation of the floors and plans for the design and realization of paths for tourists.
\end{abstract}

Keywords: World Heritage Site; UNESCO; Jordanian Cultural Heritage; Applied Technologies; Survey; Valorization; Islamic period; Archaeological; Religious structures; Pixel dimension; Tourists; Century; Community

History of Research on the Archaeological Site of Umm Ar-Rasas, Jordan

The archaeological site of Umm ar-Rasas is located $30 \mathrm{~km}$. SE to the town of Madaba in Jordan, north of the wadi Mujib on Moab's plateau and it covers approximately 10 ha. The remains consist of a huge area, fortified by a massive wall that measures $158 \times 140 \mathrm{~m}$., where numerous buildings are located and that once was a Roman Castrum. Towards the northern part of the archaeological site both dwellings and religious structures have been identified, which can be dated from the Byzantine to the Early Islamic period, up to the IX century AD [1].

The identification of Umm ar-Rasas with the ancient Kastron Mefaa, a place name known in biblical times which has been a military camp in Roman times, then an important Byzantine town and lastly a Christian city under Islamic rule, is the first result of the scientific investigations made on the area by Studium Biblicum Franciscanum [2], whose research group has worked here with the support of the Department of Antiquities of the Hashemite Kingdom of Jordan from 1986 to 2004, when the Jordanian archaeological site has been inscribed in UNESCO's World Heritage List.

The missions directed by Father Michele Piccirillo have brought to light a complex and unexpected reality: the most relevant religious complex is Saint Stephen's, by the name of the proto-deacon and proto-martyr to whom it was dedicated, a complex that had been developing between the VI and VIII century $\mathrm{AD}$, formed by at least four communicating buildings: the Church of the Tabernacle, the most ancient, Bishop Sergius' Church with its baptistery and the funerary chapel to the front, Saint Stephen's Church and the Church of the Courtyard, standing between the other three churches. Towards north, a kilometre and a half from the residential zone, an exceptional example of Stylite Tower stands 15 meters high at the centre of a courtyard protected on the northern side by a squared defensive tower nearby some water tanks dug in the rocky soil. The Stylite Tower doesn't have stairs, instead it has just one room with windows in its highest portion, thought to be a place of meditation for the Stylite monk.

The research project of the CNR-ITABC has focused on the rich mosaic decoration of Bishop Sergius' and Saint Stephen's Churches, both with three aisles and one apse and with the chancel raised by two steps. The two churches host some mosaic floors of exceptional quality and rich with inscriptions, portraits, everyday life scenes, geometrical and plant motifs and nonetheless the representation of many towns from Palestine, Egypt and Jordan. In Bishop Sergius' Church those mosaics are dated with precision to 586 A.D. by a mosaic inscription located to the front of the altar's base, where the name of the commissioner, Bishop Sergius of Madaba (576-603 A.D.), is mentioned. Through time they have been subject to modifications both for restoration and iconoclasm's reasons, such as in the case of many other contemporary religious complexes: the readability of the portions that represent figurative elements in fact has been for the most part made uneasy to perform, because of actions of 
censorship on the figurative images, realized by taking off the tesserae one by one and then putting them again in position but without a precise scheme, with the aim of filling the gaps in the floor. Also, in Saint Stephen's Church, built after Bishop Sergius' Church and dated around 717 A.D., the subjects portraying people and animals have been disfigured; however, it has to be noticed that the intervention on the figures of the mosaic floor results, for its execution mode, as made by Christian workers, who cared scrupulously about the complete preservation of the floor, either for the beauty and the decorum assured to the cultic building and for its value as an offer by local community members, whose names were written together with the images in the mosaic representations.

To comprehend the history of a place, to understand how the passing of time has brought with it different cultures with their own traditions and costumes and that each and every one of them has left a tangible sign until our times, cannot occur but through the analysis and deep knowledge of the site, the geographical and historical context, the investigation of materials and the state of conservation. All these elements contribute to the attempt at shedding light on ancient places, to make them alive again and preserve them for future generations. Focusing the attention on these needs, the problems posed must not be limited to the securing and state of conservation of these structures, but they must be made available and accessible at their full capacity as being part of mankind's heritage.

\section{Research Goals}

From 2013 the Institute for Technologies Applied to Cultural Heritage of the Italian National Research Council has started a project with the aim of valorizing the site and the work already done by the Department of Antiquities of the Hashemite Kingdom of Jordan and by the Franciscan Archaeological Institute in more than twenty years, not only from an archaeological and architectural point of view, but also to provide a better accessibility to the site and a subsequent touristic and economic development to the area. A careful documentation ad a systematic mapping of the various kinds of standing structures constitute the basis for any further conservation and restoration activity, which can be integrated favorably even at a second time with archaeological data resulting from further investigations on the field.

The archaeological missions undertaken until now have been mainly aimed at photogrammetric and laser scanning surveys to determine morphological anomalies of the mosaic floors in Saint Stephen's and Bishop Sergius' Churches at Umm ar-Rasas. The project foresees as its goal the documentation and consecutive valorization and accessibility of the site, also through the professional training of local technicians with the help of distance learning systems. During the measurements' campaigns, the work proceeded in continuity with the activities realized in the previous years and the following activities are expected to be completed soon, representing only a small portion of actions, compared to the more general framework of issues affecting the entire archaeological site:

a. The survey of the outer walls of Saint Stephen's and Bishop Sergius' Churches, either by photogrammetric methods and by detailed and high-resolution laser scanning.

b. The documentation of the decaying state of the most relevant and at high risk structures - the mosaics in SaintStephen's and Bishop Sergius' Churches - through the use and integration of high resolution laser scanning and photogrammetric methods which will highlight the decay, even the type which is not perceivable by direct sight. These methodologies produce micro DEM of the floors useful for a correct interpretation of the structural solicitations of the building that, if compared to the other parameters and measurements taken during the survey campaigns, will provide a punctual documentation useful to plan the following restoration and reinforcement actions on the mosaics. A further fundamental element for the documentation and conservation will be given by the high-resolution orthogonal pictures of the mosaic surface, arriving to a pixel dimension of a few square millimeters, allowing to obtain images with dimensions comparable to the real dimensions of the mosaic.

c. Non-invasive geophysical prospections of the areas of the main churches, which will allow detecting anomalies possibly indicating more ancient structures or graves.

An adequate representation of the state of conservation of an archaeological and architectural structure represents a fundamental means of knowledge that could guarantee the success of a restoration, valorization and accessibility project for the monument itself.

\section{Methodologies and Development of the Project}

The survey is a methodological discipline that is useful to the investigation and revision of artefacts of the past. It contributes in a fundamental way to the analysis, study and processing of interpretative models of monuments and archaeological areas. The methodological approach on the work of the last few years has been profoundly revised and updated thanks to the latest technologies and methodologies; however, it is not to be missed the critical analysis and the direct comparison to the survey or the interpretation on the field of the main elements of the monument subject to study. The use of information technology has contributed to the production of faster and more efficient equipment, making its use on the field almost undeniable. Even if the survey in this sector is often linked to a space-restricted operational field (in photogrammetry, there's the reference to "close range", also known as "near objects' range"), today we frequently witness various degrees of interventions: let's just think about the survey of a building, or better of a complex of buildings interesting from an architectural viewpoint, set in a context of numerical cartography at urban scale, or about an archaeological survey from the site to the single object's scale. 
The multi-scale term is adopted in cases in which the survey of an object made with a high level of accuracy is put in a context-based survey made with less attention to detail. Then, one is confronted with many different issues that require various kind of equipment operating with a non-consistent level of precision and different reference system, but that eventually must communicate in some ways between each other. Another aspect is the accuracy required for the survey. This can be low when the main goal is the object presentation and visualization's effectiveness or in the case of applications, e.g. in the archaeological field. Otherwise the specialized user can instead ask for restricted requirements as for the resolution and accuracy: there are examples of surveys of artefacts made with precision by the millimeter or even less, e.g. with the use of the latest scanning tools (as for the survey of an artwork with the aim of reproducing an exact copy of it) or with high level topographical tools (as for the deformations' check on a structure or on an object).

As mentioned before, there's the need to integrate in multiple cases techniques operating to different levels, or products made with different reference systems in the same survey area; in these circumstances it becomes essential first a correct planning of the work and after that the adoption of calculus' techniques or procedures allowing the link between different datasets. As for the study and documentation of the mosaic on floor of the main building of Umm ar-Rasas' site, Saint Stephen's Church, the research group chose to use non-destructive diagnostic techniques (laser scanning and photogrammetry), in combination with information technologies; in this way a great amount of relevant and reliable data related to decay events occurred on the mosaic floors have been collected and stored, with the purpose to be able to plan their conservation in the future, bearing also in mind the possibility of making a representation of the mosaics for an exhibition.

\section{Photogrammetry}

For the work on the site of Umm ar-Rasas the research group decided to set up a system allowing the complete documentation of the floor at high resolution: therefore, a photogrammetric technique (called Structure of Motion) which utilizes a great quantity of camera takes, in order to have a better chromatic definition of surfaces and a better photographic detail, has been performed. During these years almost 2000 photogrammetric takes have been acquired from the mosaic floor of Bishop Sergius' Church, with a 21 Mpixels' resolution for every single frame, standing by 1,5 metres from the floor, with the camera perpendicular to it. The images, taken in RAW format, have been calibrated in the RGB map using a predisposed chromatic table. This table has also the peculiar characteristic of being recognized automatically by a specific algorithm allowing the definition of the chromatic scale. This operation was necessary to standardize the colours of the photographic takes depending on the different level of lighting to which the floor was subject to at different hours of the day and on the different spatial positions of the camera inside the church.

\section{Laser Scanning}

To perform the survey through laser scanner on the structures subject to investigation a pneumatic pole has been used to raise the scanner up to 5 meters high, allowing in this way to measure even the highest walls' crests. This tool, designed and built specifically for this purpose, allowed performing 3D surveys from observation points that nowadays require the use of drones (that have sight from up above), without altering the geometric and metric accuracy which only laser instruments can offer. Another advantage brought by this survey technique is that the laser scanners are tools mainly made to perform scans in the architectural and engineering field; therefore, their best application is mainly addressed at everything that stands high above the planking level (walls, ceilings and arches). It is instead less efficient to measure structures that are located on the horizontal level of the instrument (floors, mosaics, holes, depressions and digs).

The scans made were 70 in total and the survey has been completed for the entire monumental structure of the two churches, Saint Stephen's and Bishop Sergius'. The scans have been executed with a resolution at a half of the maximum of the instrument and acquiring also the RGB component. The registration of the scans (e.g. to refer all the scans to the same reference system) has been made using a double process of alignment, the first based on the automatic identification of suitable 3D-targets (spheres), the second by complex mathematical algorithms that provide the refinement of the initial alignments. In fact, if through the first alignment one can identify at least three spheres in two consecutive scans, with the following process automatically starts the identification of at least 2000 common points to optimize the alignment. At the moment the research group is finishing processing all the acquired scans by isolating single elements of every building (walls, apse and floor), and then we will proceed to the modelling of the structures that will help doing in the future a virtual anastylosis of the monument.

\section{Equipment and Data Processing}

The testing conducted on a small portion of the floor (the apse of Saint Stephen's Church) in the 2013 mission had evidenced the need to build a tool allowing the realisation of the photogrammetric takes with the camera in an easy way at a fixed distance from the floor. The photogrammetric tool that has been set up is made of a camera calibrated with a $20 \mathrm{MP}$ Full Frame sensor and a $28 \mathrm{~mm}$ lens, mounted on a pole that can be put on the shoulder. The camera was constantly held to a height of $170 \mathrm{~cm}$., obtaining a very good compromise between the accuracy of the photogrammetric takes and enough dimension of the area to be acquired $\left(2 \mathrm{~m}^{2}\right.$ for each take) [3]. The research group chose to operate using an experimental tool that 
allowed more freedom in movements, considering the extreme delicateness of the surface and that the main purpose of the work was documenting the decay and avoiding damage to the building. The choice has fallen on quick and light weighted tools, easy to move on the mosaic floor. Moreover, the presence of metal structures (boardwalks) in situ has in many cases created some difficulties on taking the pictures and has limited the action range of the group to lower heights (this brought the need to take frames at a higher frequency). In general, a good quality of takes is the best guarantee of a result in which the mapping of the model is at a good level.

For each floor approximately 2000 frames have been taken, with the purpose of covering in full the surfaces of the two investigated churches (Saint Stephen: 242,26 sm.; Bishop Sergius: $226,12 \mathrm{sm}$.), also the use of a colour-checker allowed the balancing of the color white made using a raw-converter software. At every movement the operator, before taking the shot, had to assure the perfect stability of the camera, without oscillations; the movements had to allow an adequate overlapping, to guarantee, during the data processing phase, the assembling of the frames. It has to be noticed that, at each change of the light conditions, the color has been calibrated again with the help of the color -checker, to avoid chromatic differences between each stripe. The final point cloud is the result of the alignment of the various stripes. The software application, based on the technique known as Structure from Motion (Remondino et al. 2014), doesn't make the built model a metrical model; therefore, it is necessary to determine a ratio based on the topographical data at hand. Hence, the photogrammetric survey was combined to the laser scanning survey (Cundari 2012).

The scans were all performed through a phase-shift laser scanner Focus120 3D, produced by Faro, that gives high accuracy results, despite the scan timings. The instrument was set on the profile "Outdoor over 20m." with a resolution to a half of the maximum and the acquisition of the RGB component. Approximately 10 to 12 scans have been made each day since it took 30 minutes to take each scan due to the scanner configuration, considering the $8 \mathrm{hrs}$ of overall duration of the two batteries at hand and the timings of movement of the pneumatic pole and the instrument. The registration [4] of the scans has been made using a double alignment process, the first based on the automatic identification of suitable 3D high reflectance white targets (spheres) provided by Faro, with a $20 \mathrm{~cm}$. diameter and a magnet allowing their attachment to metal structures [5]; the second required the use of complex mathematical algorithms providing the refinement of the initial alignments. When surveying with this technique, one must account for three factors to get a good automatic alignment: first, at least three spheres must be visible in between two adjacent scans, secondly the scans must have a suitable spatial distribution and lastly the laser scanner must find enough points on the scans to recognize them and then calculate precisely their centre [6].
Once it has aligned the scans through the help of the spheres, the software automatically proceeds to the identification of at least 2000 common points to refine the alignment, resulting with an average error in the range of a millimetre.

\section{Future Outlooks of the Projects}

The site of Umm ar-Rasas constitutes an extraordinary laboratory to study traditional masonry, either for the different use of materials in time and for the construction techniques' development. The settlement's long evolutionary history, that has its roots in the Roman castrum's implant, allows to analyze in a critical way the different typologies adopted for common houses and specialized building, such as the numerous Medieval churches that have developed according to environmental conditions and materials' availability at the local level. The instability modes of the structures that have survived to time and earthquakes' action, typical destructive events that occur in this area, are an aspect of great interest. This issue of the research can be studied beginning from the site currently under investigation and then be extended to a wider environmental context, with effects on the western world through a comparison with other construction traditions that are affected by the same issue. Therefore, this site offers a unique opportunity to understand the construction techniques' evolution putting the accent on anti-seismic actions [7,8]. There are open questions about the static and seismic behavior of the arches and more generally of the pushing structures, considered among the most vulnerable structures but also some of the few that have survived to the general framework of instability. The study of the masonry through the mechanics of the arches constitutes the interpretation key that puts Umm ar-Rasas as a key site for the analysis of these events in an environment that keeps its original construction characteristics.

Analyses requiring superficial and underground observations of the soil and of the lithological and petrographically characteristics of the rocky subsoil have started on the area on which stands the so called Stylite Tower, this being among the most relevant structures of the archaeological complex. Moreover, the use of equipment such as georadar and geoelectric and seismic systems, both active and passive, will be implemented. Lastly, the identification of the structural mechanical characteristics and the decay, vulnerability and stability level caused by the atmospheric agents will be performed through the petrographical analysis and the direct topographical laser scanning survey [9-12]. Another part will provide the realization and development of a tool for the valorization and availability of the data by a wider range of users: the geodatabase of the mosaic floor in Saint Stephen's Church will allow the creation of a model for computerized management and interdisciplinary data analysis aimed at interpretation, conservation and valorization. In the next paragraph the research phases that are currently being developed to realize the geodatabase of the mosaic floor in Saint Stephen's Church are illustrated. 


\section{Gis Technology Application on Umm Ar-Rasas Archaeological Site}

The creation of the geodatabase is the result of the partnership and debate between the members of the research group made by archaeologists, art historians, geophysics and conservators. The geodatabase is developing in time following some steps: beginning with the development of a GIS platform to archive the acquired interdisciplinary data, to the development of analysis models for data management. Therefore, the GIS technology offers both methodological and interpretative advantages: from one point of view it allows the realization of an interdisciplinary dialogue between different research matters through the efficient data management and registration; from another point of view it makes easy to interpret the information acquired from the spatial queries. Also, the geodatabase can be used as a monitoring device on the state of conservation of the mosaic, becoming a valid support for the planning of future restoration actions [13-15].

\section{Public Accessibility to the Site}

An important part of the project will be dedicated to planning paths for the accessibility of the archaeological site, especially in the Roman Castrum, by realizing two main itineraries: one external to the surrounding wall and one on the inside related to the south-eastern quarters of the Castrum. As for this last one, it will be necessary to plan a path that goes along the course of the walls, starting from the north-western angle and proceeding counter clockwise towards the existing entrance at the southeastern angle from where there's access to the previously mentioned quarters of the Castrum. A secondary path will be realized in the area extending to the north of the Castrum, where a pre-existing itinerary goes between the buildings and insulae characterized by the presence of churches linked to service rooms and autonomous hydraulic systems. In this case also there's the need to provide road access to the different insulae to highlight the existence of multiple religious complexes, all independent from one another from an urban point of view (services and infrastructures). The planning is set as to provide first a general map of the site with the structures brought to light in the previous digging seasons and with the still unexcavated features thanks to the combined use of drone and topographical processing software.

\section{Results and Conclusion}

Each survey performed at Umm ar-Rasas has given us a better knowledge of the structures located on the archaeological site. It should be also noticed that all the technologies employed resulted in new issues to be solved in the future with further applications [16-18]. The work conducted until now has been a useful experiment for the integration of laser scanning and photogrammetric surveys: in this way the results guarantee from one side the descriptive accuracy in the colors and in the details of the surveyed surface; from another point of view the use of the laser scanning methods allows the representation with great precision, in the range of a few millimeters, of the geometrical deformities of the mosaic floors. The final product is an orthogonal picture of the whole floor.

By analyzing the floor of Bishop Sergius' Church it has been pointed out a lifting of the floor by $0,10 \mathrm{~m}$ in the central aisle towards the apse; instead it has been noted a depression in the zone near the entrance door, the presence of which is probably related to an underground water tank located on the northwestern side if the building, where traces of a water channel are visible. In Saint Stephen's Church there are also liftings of the floor on the right side of the central aisle, while light slopes are visible on the rest of the floor, especially on the portion of floor that is nearer to Bishop Sergius' Church. The causes of these deformities are unknown now, but they could be linked either to geological instability issues of the area and to further underground man-made structures (graves, mural structures, tanks). The following investigations are aimed at the secure interpretation of these deformities. In relation to this, the execution of high resolution photogrammetric surveys could be used as a starting point for any conservation and restoration project to be planned for the preservation of the mosaic floors.

\section{Acknowledgement}

A special thanks goes to Mr. Pasquale Galatà 6 who has edited all the photogrammetric frames and the data processing, also taking care of the perfect efficiency and maintenance of the equipment on the site.

\section{References}

1. Conyers LB, Goodman D (1997) Ground Penetrating Radar: An Introduction for Archaeologists. Walnut Creek, Alta Mira Press, California, USA.

2. Cundari C (2012) Il rilievo architettonico. Ragioni. Fondamenti. Applicazioni. Kappa, Rome, Italy.

3. Goodman D, Piro S (2013) GPR Remote sensing in Archaeology. Springer, Berlin, Germany.

4. Ognibene S (2002) La chiesa di Santo Stefano a Umm al Rasas ed il problema iconofobico. Rome, L'Erma di Bretschneider, Italy.

5. Piccirillo M (1994) mm al-Rasas a faa (Gli scavi del complesso di Santo Stefano). Jerusalem, Studium Biblicum Franciscanum, Israel.

6. Piccirillo M (2008) La Palestina cristiana I-VII secolo. Bologna. Centro editoriale dehoniano (EDB), Italy.

7. Decision: 37 COM 7B.51 Umm ar-Rasas (Kastrom Mefa'a) (Jordan) (C 1093).

8. Nahhas R (2016) Unesco World Heritage site, Jordan's Umm ar-Rasas seeks recognition. The Arab Weekly 75: 24 .

9. https://whc.unesco.org/en/criteria/.

10. Umm ar-Rasas: a basis towards a Public Use Plan.

11. Site Management Planning.

12. Excerpt retrieved from: Secondary Cities Development Study (2005) Annex A p.3-4.

13. Law No 21 (1988) promulgated in the Official Gazette. issue No. 3540 
dated 17/3/1988 and amended in 2002 (amendment No. 23), 2004 (amendment No. 23) and 2008 (amendment No. 55).

14. Law No 5 (2005) on the Protection of Architectural and Urban Heritage. ruling the protection and management of cultural heritage dating after year AD 1750

15. Law 12/1987 and its amendments, Law for the Purchasing of Land for Public Use.
16. Law No. 7/1993, Building Law.

17. Regulations for Archeological Excavations and Surveys in Jordan 2015

18. Technician Institute for Technologies Applied to Cultural Heritage, Italian National Research Council (ITABC CNR), Italy.

\section{Your next submission with Juniper Publishers will reach you the below assets}

- Quality Editorial service

- Swift Peer Review

- Reprints availability

- E-prints Service

- Manuscript Podcast for convenient understanding

- Global attainment for your research

- Manuscript accessibility in different formats

( Pdf, E-pub, Full Text, Audio)

- Unceasing customer service

Track the below URL for one-step submission

https://juniperpublishers.com/online-submission.php 